\title{
A EFICÁCIA EXPANSIVA DAS DECISÕES NO NOVO CPC: DO INSTITUTO DE ASSUNÇÃO DE COMPETÊNCIA E DO INSTITUTO DE RESOLUÇÃO DE DEMANDAS REPETITIVAS
}

\author{
THE EXPANSIVE EFFECTIVENESS OF DECISIONS IN THE NEW CPC: \\ INSTITUTE OF ASSIGNMENT OF COMPETENCE AND INSTITUTE OF \\ RESOLUTION OF REPETITIVE DEMANDS
}

Recebido em 02/10/2017

Aprovado em 08/04/2018

\author{
DANILO HENRIQUE NUNES1 \\ LUCAS SOUZA LEHFELD ${ }^{2}$
}

\begin{abstract}
RESUMO: O artigo se propõe ao estudo do sistema obrigatório de precedentes contextualizado no novo Código de Processo Civil, à luz dos princípios constitucionais. Questiona-se se o sistema de precedentes está em consonância com a promessa do novo códex, que é promover um processo civil constitucionalizado. O método utilizado para a construção científica foi no campo da pesquisa bibliográfica, nas áreas dedutiva e indutiva. A primeira por meio do estudo do Direito Processual Civil sob a ótica do Direito Constitucional. A pesquisa partiu da legislação, alcançando conceitos e estudos doutrinários sobre o tema. A segunda perfazendo o estudo da realidade, especialmente no tocante ao respeito dos precedentes no país. É possível concluir que os princípios constitucionais não serão suprimidos em razão da observância dos precedentes, isso porque coexistirão em prol da efetiva segurança jurídica da atividade jurisdicional e da isonomia, alcançando um processo justo e com resultados satisfatórios. Não haverá, portanto, conflito de normas, mas sim interpretação conjunta dos princípios constitucionais e do sistema de precedentes para efetivar o direito brasileiro.
\end{abstract}

PALAVRAS-CHAVE: Precedente judicial, Conflito de normas, Processo civil constitucionalizado.

\begin{abstract}
The article proposes to study the mandatory system of precedents contextualized in the new Code of Civil Procedure, in light of constitutional principles. It is questioned whether the system of precedents is in line with the promise of the new codex, which is to promote a constitutional civil process. The method used for scientific construction was in the field of bibliographic research, in the areas of deductive and inductive. The first one through the study of Civil Procedural Law from the point of view of Constitutional Law. The research started from the legislation, reaching doctrinal concepts and studies on the subject. The second is the study of reality, especially with regard to respect for precedents in the country. It is possible to conclude that the constitutional principles will not be abolished due to the observance of the precedents, because they will coexist in favor of the effective juridical security of the jurisdictional activity and the isonomy, reaching a fair process and with satisfactory results. Therefore, there will be no conflict of norms, but a joint interpretation of the constitutional principles and the system of precedents to effect Brazilian law.
\end{abstract}

KEYWORDS: Judicial precedent, Conflict of norms, Constitutional civil process.

\footnotetext{
1 Advogado militante nas áreas de Direito Constitucional, Tributário e Administrativo (de modo especial, licitações) com especialização em Direito Processual Civil e Didática para Ensino Superior pelo Centro Universitário da Fundação Educacional de Barretos e em Direito Constitucional pela Faculdade de Direito Damásio de Jesus. Mestrando bolsista da CAPES em Direito pela Universidade de Ribeirão Preto

2 Professor-doutor orientador do programa de Mestrado em Direitos Coletivos e Cidadania da Universidade de Ribeirão Preto
} 


\section{INTRODUÇÃO}

No Brasil, a promoção e garantia da segurança jurídica nasce da aplicação da Lei. A Lei como fonte primária, consiste no instrumento apto a solucionar controvérsias levadas aos Tribunais, ou seja, o direito é positivado e concede ao juiz a função de intérprete e aplicador da lei. O princípio da legalidade está contextualizado no art. $5^{\circ}$, inciso II da Constituição Federal e consolida tal previsão, esculpindo entrelinhas o sistema adotado pelo ordenamento jurídico pátrio, o civil law, protegendo o indivíduo e norteando a atividade jurisdicional.

No sistema civil law, o direito é aplicado de forma objetiva e se caracteriza como mecanismo de cumprimento da segurança jurídica, prevalecendo a vontade do Estado como órgão soberano e, a atividade jurisdicional, como instrumento de aplicação da lei. O commow law, fundamenta-se no direito costumeiro, utilizando-se da jurisprudência para pacificar os conflitantes. Se no civil law busca-se segurança jurídica, no commom law busca-se a harmonização e reconciliação das partes, pouco importando qual foi o meio adotado para alcançar o resultado, se a lei ou o precedente. Isso significa dizer que o commow law não ignora a aplicação da lei, mas prestigia a harmonização das partes e solução do conflito.

Na sistemática de common law a decisão judicial se presta a uma dúplice função: decide o caso concreto (res judicata) e estabelece-se como precedente a ser observado no futuro. Desta forma, pode-se afirmar que essas decisões judiciais têm a mesma força das leis, e não são meros mecanismos de interpretação. Para Charles D. Cole a decisão da Corte que constitui precedente, efetivamente é lei, pois determina o que significa a Constituição dentro da esfera de competência que cabe à Corte, seja ela estadual ou federal. ${ }^{3}$

A escola commow law se baseia, primordialmente, nos costumes. Amparada pela teoria do stare decisis este sistema adota, sobretudo, a particularidade de cada caso para que seja proferida uma decisão, pacificando os envolvidos. Essa teoria busca, obrigatoriamente, manter o que for decidido. Diferente da civil law, que prescinde da aplicação do precedente, mas o utiliza como auxiliar na interpretação da lei.

Oportuno esclarecer uma possível confusão entre os institutos precedentes, commow law e civil law. Para correta interpretação, não se deve relacionar força normativa dos precedentes intrinsecamente a países de commow law. Erroneamente, há quem diga que o

3 KOOPMANS, Thomas. Stare decisis in European Law. Leiden University Repository. Disponível em: $<$ https://openaccess.leidenuniv.nl/handle/1887/22742>. Acesso em 23 jun. 2017. 
Brasil está se transformando em um país de commow law. Interpretar nesse sentido é desrespeitar uma tradição cultural do Brasil, bem como dos países commow law. Não é possível transformar uma tradição. No mesmo sentido, é ilógico interpretar como sinônimo respeito aos precedentes e sistema commow law, ou seja, não se deve conceber o commow law apenas num sistema de respeito aos precedentes e vice e versa. Logo, é plenamente possível falar em commow law sem sistema obrigatório de precedentes e civil law com sistema obrigatório de precedentes. ${ }^{4}$

É um erro pensar que o sistema brasileiro é incompatível com os precedentes, até porque o sistema normativo de precedentes já existe no Brasil, inobstante faltasse normatização do sistema. Ou seja, desde o século XIX há o respeito às orientações do Supremo Tribunal Federal. Além disso, decretos foram criados, súmulas editadas e mudanças legislativas ocorreram, reforçando o sistema dos precedentes.

No Brasil, portanto, existe uma tradição de normas que impõe o respeito aos precedentes, mesmo que ainda não existisse previsão legal de um sistema que determinasse tal conduta. Ao longo dos anos, os precedentes ganharam corpo no Código de Processo Civil de 1973, com a aprovação dos artigos $285-\mathrm{A}, 481$, parágrafo único, 557,475 , $\S 3^{\circ}$, e $581, \S 1^{\circ}$. O novo Código de Processo Civil, por sua vez, passa a prever, acertadamente, os precedentes judiciais com observância obrigatória, à luz da Constituição Federal.

Assim, relevante e indispensável o estudo acerca deste sistema que inova o ordenamento jurídico brasileiro, fazendo-o evoluir de forma considerável, especialmente, para fazer cumprir a promessa do novo CPC, que é promover um processo constitucionalizado, próximo ao direito material, de modo a garantir a segurança jurídica.

\section{OS PRECEDENTES NO NOVO CÓDIGO DE PROCESSO CIVIL}

\subsection{CONCEITOS FUNDAMENTAIS}

\subsubsection{Ratio decidendi e obiter dictum}

${ }^{4}$ DIDIER JR, Fredie; BRAGA, Paula Sarno; DE OLIVEIRA, Rafael Alexandria. Curso de Direito Processual Civil: teoria da prova, direito probatório, ações probatórias, decisão, precedente, coisa julgada e antecipação dos efeitos da tutela. 11 ed. Salvador: Editora JusPodivm, 2016, p. 535-536. 
Em termos gerais, a decisão consiste em fundamentação e dispositivo. Na fundamentação é demonstrada a existência de uma norma jurídica geral do caso concreto, de onde decorre a norma individualizada. No dispositivo, é fixada a norma jurídica do caso concreto de forma individualizada, regulando o caso em apreciação. É sobre a norma individualizada que recai a coisa julgada, estabilizando a decisão, resolvendo a lide.

A norma jurídica geral serve para inúmeras situações, ou seja, destina-se a casos hipotéticos construídos a partir de um caso, fundamentando sua solução e servindo de modelo para a solução de casos futuros semelhantes. Assim, nasce o precedente judicial. Ele nada mais é do que a conjuntura do problema originário (o caso), da norma jurídica geral construída para resolvê-lo e da argumentação jurídica desenvolvida para a solução. Por isso, a decisão judicial passa a ser vista a partir de uma dupla perspectiva, como solução de um caso e como um precedente.

O dispositivo da decisão apresenta a solução do caso e a fundamentação apresenta o precedente. Inobstante a presença dos três elementos (caso, argumentação jurídica e norma jurídica), o precedente tem como núcleo a norma jurídica geral construída. Essa norma do precedente é a ratio decidendi, que consiste no fundamento normativo da decisão, ou seja, o dispositivo decorre da ratio decidendi, porque ela é a norma geral que se encontra na fundamentação do julgado, da qual decorre a norma individualizada encontrada no dispositivo. Além disso, ela é universalizável, porque tem aptidão para ser aplicada em outros casos. A melhor tradução do termo ratio decidendi é a razão de decidir.

[...] ratio decidendi são os fundamentos jurídicos, a opção hermenêtica ou a tese jurídica que sustentam a solução de determinado caso concreto, sem os quais a norma individual não teria sido formulada daquela maneira. Segundo, a ratio decidendi é a norma jurídica geral, que construída por um órgão jurisdicional, a partir de um caso concreto, pode servir como diretriz no julgamento de demandas semelhantes. 5

A razão de decidir construída a partir da solução de um caso quando aplicada de forma reiterada em outros casos forma a jurisprudência, que por sua vez, é a reiterada aplicação de um precedente. No Brasil, tanto o precedente quanto a jurisprudência produzem efeitos jurídicos, desmistificando a ideia de que apenas a jurisprudência tem força normativa

5 DIDIER JR., Fredie; BRAGA, Paula Sarno; OLIVEIRA, Rafael. Curso de direito processual civil. 8. ed. rev., ampl. e atual. Salvador: JudPodivm, 2016, v. 2., p. 427-428. 
obrigatória. A súmula é um enunciado, ou seja, é o texto da ratio decidendi, aplicada reiteradamente nos Tribunais.

O precedente interpreta a Lei construindo a ratio decidendi, que aplicada reiteradamente se transforma em jurisprudência, podendo se transformar em enunciado de súmula, que é o texto de uma norma criada a partir de um caso. Logo, partindo desse raciocínio a norma só pode ser interpretada à luz do caso originário. Até porque, a redação da súmula deve respeitar as circunstâncias fáticas dos precedentes que a motivaram. A ratio decidendi por ser de conteúdo processual ou material, podendo existir em duplicidade.

Entretanto, nem tudo que está na fundamentação é ratio decidendi. Ao conjunto de manifestações laterais e pessoais que não servem como fundamento se dá o nome de obiter dictum, que consiste nos argumentos jurídicos expostos apenas de passagem na motivação da decisão, por isso, não podem ser precedente. Não fazer parte da razão de decidir de um caso não impede de estar presente em outro. O obter dictum não é inútil, podendo indicar um comportamento futuro do respectivo Tribunal, pois ele revela:

a) juízos normativos acessórios, provisórios e secundários; b) impressões ou qualquer elemento jurídico-hermenêutico que não tenham influência relevante para a decisão; c) opiniões jurídicas adicionais e paralelas, mencionadas incidentalmente pelo juiz, dispensáveis para a fundamentação e para a conclusão da decisão. ${ }^{6}$

Se não é razão da decisão, o voto vencido nada mais é do que o obiter dictum, que está na fundamentação da decisão, não sendo determinante, e sim lateral, acessório.

\subsubsection{Distinguishing e overruling}

A aplicação do precedente prescinde da comparação entre o caso concreto e a razão de decidir, o julgador deve apreciar se o caso paradigma se assemelha com aquele que será julgado. Essa comparação recebe o nome de distinguishing, pois se destina a individualizar o direito, distinguindo-o.

Apesar de ser obrigatório, o precedente não terá lugar em qualquer hipótese, isso porque a obrigatoriedade está em sem enfrentamento e não em sua aplicação. Haverá fatos que não guardam relação de semelhança, mas exigem a mesma conclusão jurídica, bem como

\footnotetext{
6 JESUS, Priscilla Silva de. Teoria do precedente judicial e o novo código de processo civil. Disponível em: < http://www.revistas.unifacs.br/index.php/redu/article/view/3240>. Acesso em: 05 jun. 2017.
} 
fatos que guardam semelhança, mas a peculiaridade de cada caso individualizado os tornará substancialmente diferentes. 7

A motivação é a principal característica do distinguishing, consoante art. 93, IX, Constituição Federal. Devendo ser observadas a Lei, os conceitos, as súmulas e as emendas, somadas aos elementos fáticos e jurídicos.

Por sua vez, overruling consiste no confronto do caso com a razão de decidir do paradigma, revogando-o ou superando-o à luz das mudanças dos valores sociais, dos conceitos jurídicos, da tecnologia ou de erro que pode gerar instabilidade. Isso significa dizer que embora o caso paradigma se aplique ao caso sob julgamento, por fatores diversos não há conveniência na sua aplicação, ou seja, não é mais conveniente preservar o precedente. Uma vez revogado, o precedente recebe nova posição jurídica a ser construída pelo órgão legitimado. ${ }^{8}$

Overruling ocorre "quando há uma superação total do precedente, o que pode acontecer tranquilamente, sendo esta a diferença entre o precedente e a coisa julgada, uma vez que esta é indiscutível, somente podendo ser revista basicamente, por rescisória". 9

Nos processos em andamento e nos que ainda serão instaurados aplicar-se-á a regra da retroatividade, sem importar o momento da constituição da relação jurídica. Nos casos onde já produziu coisa julgada, a res judicata, e em alguns casos quando houver o direito adquirido, aplicar-se-á a regra da irretroatividade, tendo em vista a imutabilidade. Isso porque, as normas do tempo é que regem o ato.

A impossibilidade de conferir efeitos prospectivos pode gerar insegurança jurídica, isso significa dizer que, a norma deveria evitar que o autor vencedor na instância inferior fosse surpreendido com a mudança brusca do entendimento já firmado. O art. $5^{\circ}, \mathrm{XXXVI,} \mathrm{CF}$ garante certa previsibilidade do resultado de certas demandas, proporcionando maior segurança jurídica. No Brasil, a eficácia prospectiva (prospective overruling) está presente no controle de constitucionalidade, art. 27, Lei 9.868/1999. 10

\footnotetext{
7 DONIZETTI, Elpídio. A força dos precedentes no Novo Código de Processo Civil. Disponível em: < www.revistas.unifacs.br>. Acesso em: 01 jun. 2017.

8 DONIZETTI, Elpídio. Op cit.

9 LOURENÇO, Haroldo. Precedente judicial como fonte do direito: algumas considerações sob a ótica do novo CPC. Disponível em: <www.agu.gov.br/page/download/index/id/11458380>. Acesso em 30 mai. 2017.

10 DONIZETTI, Elpídio. Op. Cit.
} 
A técnica de superação overruling se destina à superação do precedente, exigindo, evidentemente, maior cautela no momento de sua superação, cuidando para que sua fundamentação respeite e preserve situações já consolidadas, inobstante o seu objetivo seja manter o sistema oxigenado.

\subsection{OS PRECEDENTES VINCULANTES À LUZ DOS PRINCÍPIOS CONSTITUCIONAIS}

A Constituição Federal enquanto Carta Republicana do Brasil prevê princípios que asseguram direitos básicos e essenciais ao indivíduo, pessoa humana. Além disso, garante seu devido e efetivo cumprimento, seja por meio do Estado ou através da aplicação da lei. Os princípios constitucionais recebem tamanha importância porque estão ligados com a essência do ser humano, por isso a necessidade de que todas as demais legislações brasileiras atuem respeitando a Carta Magna. A respeito da imprescindibilidade e importância dos princípios:

[...] os primeiros princípios estão fundamentados na estrutura ôntica do ser, sendo que em cada ente particular e concreto é possível deparar com algo de positivo e de consistente que oferece a sustentação real àquela coisa e enseja que a mesma se torne objeto de cognição. E bem aquilo que dá o ser e faz o ser inteligível recebe o nome de essência. 11

Zaiden Geraige Neto ensina que é imprescindível a noção de princípio para qualquer estudo que se pretenda iniciar, uma vez que o estudo de um princípio, de natureza constitucional é de fundamental importância para a aplicação da Direito.

Justifica-se, portanto, o estudo dos precedentes à luz dos princípios constitucionais.

Objetivando um processo civil constitucionalizado, o novo Código de Processo Civil estruturou o sistema normativo de precedentes, tornando inevitável a discussão do assunto no âmbito jurídico e também na sociedade. Necessário esclarecer, que o Brasil não está se transformando em país commow law, mas simplesmente cumprindo sua tradição de respeito aos precedentes, notadamente, através de um sistema próprio e compatível com o ordenamento jurídico pátrio.

Embora não tenha se tornado commow law, o novo códex se utiliza de alguns dos fundamentos desse sistema, especialmente, a teoria do stare decisis para uniformar e

11 FERACINE, Luiz. Os primeiros princípios do saber. SoLivros/Uniderp, 1999 apud GERAIGE NETO, Zaiden. O princípio da inafastabilidade do controle jurisdicional: art. $5^{\circ}$, inciso XXXV. da Constituição Federal. São Paulo: Editora Revista dos Tribunais, 2003, p. 17. 
estabilizar os procedentes. Há três condições favoráveis ao desenvolvimento do princípio do stare decisis. O primeiro deles é propiciar um ambiente em que as principais regras sejam não escritas. Em segundo lugar, a Corte ostentar um papel unificador no contexto de um sistema judicial com forças centrífugas. E por fim, um sistema em que seja necessário recorrer a princípios, os quais são concretizados e interpretados exatamente pela ação das Cortes.

O legislador, certamente, busca dar efetividade ao processo e garantir preceitos constitucionais, contudo, prevalece a adoção formal da aplicação objetiva da Lei, inobstante a presença codificada da teoria do stare decisis no sistema processual brasileiro, que inova ao implantar, através do novo CPC, a força obrigatória dos precedentes. Os precedentes estão presentes em todo e qualquer ordenamento jurídico, independente da adoção do sistema, variando apenas o grau de eficácia.

Por isso, propõe-se analisar em termos gerais o sistema obrigatório de precedentes à luz dos princípios constitucionais, especialmente, o aparente conflito de normas e a efetiva promoção da segurança jurídica. A noção de vinculação a precedentes pode ser decomposta em princípios, são eles: i) princípio da constância, que aconselha contrariamente a mudanças mesmo que sutis em precedentes estabelecidos; ii) princípio da generalidade: reclama que os juízes profiram decisões fundadas em normas gerais, não permitindo que os casos figurem como particularidades; iii) princípio da responsabilidade institucional: exige que o juiz subsequente reconheça o uso pelo precedente de certa norma geral; iv) princípio da fidelidade ao Direito: recomenda que cada juiz, diante de um caso não explicitamente regulado, procure aquilo que na hipótese possa ser considerado a exigência do Direito, a regulação, mesmo que implícita, decorrente do sistema de Direito (não apenas da lei).

É importante esclarecer, que pode ser um equívoco pensar no sistema de precedentes como ferramenta que engessaria o direito, impedindo sua evolução. Pois, uma vez que a Lei não é capaz de engessá-lo e mecanizá-lo, não estaria o precedente destinado a isso, uma vez que o precedente é fonte do direito, assim como a Lei.

O sistema obrigatório de precedentes pretende alcançar a igualdade, a confiança e a previsibilidade. Isso porque, à luz de um processo constitucionalizado é indispensável que o judiciário trate todos os jurisdicionados de forma igualitária, promovendo a segurança jurídica através de decisões previsíveis e diminuindo o volume de demandas, ao inibir a propositura de causas temerárias e garantindo a duração razoável do processo ao simplificar o debate. 
Promove ainda a racionalidade do processo, porque não submete o caso ao voluntarismo do julgador, impedindo que decisões arbitrárias sejam proferidas de acordo com o que o julgador reputa correto, evitando instabilidade.

[...] a segurança e a previsibilidade são aspectos de capital importância no contexto de nossa justiça, e, como se sabe, não são raras as vezes em que encontramos decisões completamente diferentes, para situações absolutamente idênticas. [...] referida situação fere os princípios da legalidade e da isonomia, previstos na Constituição da República, uma vez que a lei deve tratar a todos de modo uniforme c que, correlatamente, as decisões dos tribunais não podem aplicar a mesma lei de forma diferente a casos absolutamente idênticos, num mesmo momento histórico. ${ }^{12}$

É necessário compreender o processo não só como um meio de resolver uma lide, mas sim como meio que fixa um precedente para resolver outros casos. Assim, cada processo servirá a um só tempo para resolver o problema que foi submetido ao judiciário e fixar precedente para resolver casos futuros idênticos àquele. Portanto, o processo é hoje um método de julgamento de caso e de construção do precedente. Por isso, indispensável repensar alguns princípios constitucionais, especialmente o que se entende por contraditório e motivação das decisões. 13

O princípio do contraditório deixa de ser visto apenas como uma discussão em torno da solução do caso, e passa a ser visto também como uma discussão em torno da fixação do precedente para casos futuros semelhantes àquele ora analisado. Torna-se, portanto, uma técnica de discussão de formação de precedente. 14

Para Haroldo Lourenço “a decisão não cria somente a norma jurídica individualizada; cria norma geral, a ratio decidendi, ou seja, a tese jurídica estabelecida na fundamentação do julgado e, nesse sentido, há um direito de participação na construção da norma jurídica”. 15 A exemplo da intervenção do amicus curiae, que amplia a atuação da intervenção de terceiros, auxiliando na construção do precedente.

Por sua vez, a motivação das decisões passa a ser encarada a partir de uma dupla função, para as partes alcançando a solução do caso; e para a coletividade, alcançando os demais jurisdicionados, uma vez que a fixação dos precedentes pode atingir a coletividade.

\footnotetext{
12 GERAIGE NETO, Zaiden. Op cit., p. 105.

13 DIDIER JR, Fredie; BRAGA, Paula Sarno; DE OLIVEIRA, Rafael Alexandria. Op. cit., p. 535-536.

14 Id., ibid., p. 537.

15 LOURENÇO, Haroldo. Op. cit.
} 
[...] diante da teoria do precedente, a função extraprocessual deve ser reforçada, identificando exatamente as questões de fato que se reputam como essenciais ao deslinde da causa e se delimite, precisamente, a tese jurídica acolhida, justamente porque a fundamentação será a norma geral, um modelo de conduta para a sociedade, principalmente para os indivíduos que nunca participaram daquele processo, e para os demais órgãos do Judiciário, haja vista ser legitimante da conduta presente. ${ }^{16}$

No que tange à segurança jurídica vale destacar que para o sistema civil law apenas é possível alcançar a segurança jurídica com a observância pura e simples da Lei. No entanto, é evidente que a interpretação da Lei pode ser feita a partir da percepção moral do julgador. Feita essa constatação, soluções idênticas para casos idênticos e decisões semelhantes para demandas com o mesmo fundamento jurídico, por consequência, promoveria a segurança jurídico no momento em que o direito se torna previsível e estável. 17

\footnotetext{
[...] quanto mais uniformizada a jurisprudência mais se fortalece a segurança jurídica, garantindo ao jurisdicionado um modelo seguro de conduta, induzindo confiança, possibilitando uma expectativa legítima do jurisdicionado. A orientação jurisprudencial predominante em um determinado momento presta-se a que o jurisdicionado decida se vale ou não a pena recorrer ao Poder Judiciário em busca do reconhecimento de determinado direito. 18
}

O sistema de precedentes alcançará, principalmente, a igualdade. Isso porque "não se pode admitir que o mesmo caso concreto, enfrentado por jurisdicionados diferentes, receba decisões diferentes". 19

É razoável diferenciar os fundamentos que formam os pilares da decisão das circunstâncias de fato, dos argumentos acessórios, das razões do voto vencidos e dos fundamentos não referendados. Isso porque, estes não são obrigatórios e não assumem forma vinculativa.

\subsection{EFEITOS DO PRECEDENTE}

O novo CPC trouxe a obrigatoriedade de fundamentação dos atos judiciais, sendo o juiz obrigado a fundamentar sua decisão, explicitando os motivos que o levou a seguir o

\footnotetext{
16 Id., ibid.
}

17 DIDIER JR, Fredie; BRAGA, Paula Sarno; DE OLIVEIRA, Rafael Alexandria, op. cit., p. 535.

18 LOURENÇO, Haroldo, op. cit.

19 WAMBIER, Teresa Arruda Alvim. Estabilidade e adaptabilidade como objetivos do direito: civil law e common law. In: Revista de Processo, São Paulo: RT, v. 172, ano 34, p. 129, jun. 2009. Disponível em: < http:// w w w. e g o v. u f s c. b r / p o r t a l / s i t e s/d e fa u 1 t $/ \mathrm{f}$ i 1 e s/ estabilidade_e_adaptabilidade_como_objetivos_do_direito_civil.pdf $>$. Acesso em: 03 jun. 2017.p. 15. 
precedente no caso concreto, utilizando para tanto a distinção. Se decidir pelo afastamento da aplicação do precedente também deverá fazê-lo fundamentadamente, indicando a distinção entre o precedente e o caso concreto ou se o enunciado já foi superado.

Eficácia é o efeito automático atribuído pela Lei à determinada decisão, não decorrente da vontade do juiz, melhor dizendo, são efeitos que decorrem da ratio decidend. Logo, a eficácia do precedente nada mais é do que a eficácia da razão de decidir.

Os dois principais efeitos dos precedentes são o persuasivo e o obrigatório. Persuasivo é o efeito retórico, que serve ao menos para tentar convencer o juiz de suas ações. É um efeito mínimo e ele está em qualquer precedente, ou seja, todo precedente tem no mínimo o efeito persuasivo. O obrigatório, por sua vez, exige que o precedente seja seguido. Importante esclarecer que nem todos são obrigatórios, mas todos são persuasivos. 20

No tocante ao efeito obrigatório, vinculativo e normativo do precedente, o art. 520, caput, do novo CPC, determina a uniformização da sua jurisprudência e a manutenção da estabilidade, integralidade e coerência de suas decisões, garantindo isonomia e segurança jurídica. 21

No entanto, no direito brasileiro a eficácia vai além desses dois efeitos. Há pelo menos mais quatro efeitos dos precedentes, são eles: obstativo, autorizante, rescindente e revisional. Efeito obstativo consiste em precedentes que obstam postulações, recursos, demandas, remessa necessária, ou seja, se neste caso, a decisão estiver em consonância com determinados precedentes, a remessa necessária será obstada. Autorizante é o efeito que autoriza tutela antecipada. Se o pedido estiver em consonância com determinado precedente, ele vai autorizar a tutela antecipada. $\mathrm{O}$ efeito rescindente ocorrerá quando um precedente do STF (Supremo Tribunal Fedeeral) em controle de constitucionalidade servir de fundamento para a rescisória de uma decisão, nos termos do art. 525 do novo CPC. Quando uma sentença regula uma relação jurídica que se prolonga no tempo e sobrevier um precedente contrário àquela decisão, a decisão terá que ser revista, surtindo o efeito revisional do precedente. 22

Os efeitos dos precedentes servem especialmente para que os advogados e julgadores não embasem suas teses em votos vencidos ou em precedentes que não se enquadram no caso

\footnotetext{
20 DIDIER JR, Fredie; BRAGA, Paula Sarno; DE OLIVEIRA, Rafael Alexandria. Op. Cit. p. 518.

21 JESUS, Priscilla Silva de. Op. Cit.

22 DIDIER JR, Fredie; BRAGA, Paula Sarno; DE OLIVEIRA, Rafael Alexandria. Op. Cit. p. 519-524.
} 
concreto, observando o princípio do devido processo legal e da celeridade processual, uma vez que obsta a utilização de fundamentos em precedentes na qual as partes não tenham se manifestado, garantindo estabilidade e acesso a justiça.

Os pontos positivos oriundos dos efeitos deste novo instituto justificam sua inclusão na reforma do novo código de processo civil. Isso porque o stare decisis assegura a continuidade, promovendo estabilidade jurisdicional; igualdade de tratamento, nos termos do princípio da isonomia; poupa o Judiciário de reanálises seguidas da mesma questão, cumprindo a economia e celeridade processual; além de proporcionar previsibilidade.

\subsection{ASPECTOS GERAIS DOS PRECEDENTES}

Um precedente obrigatório jamais poderá ser ignorado. Ele pode ser aplicado, desde que observe art. 489, $\S 1^{\circ}, \mathrm{V}, \mathrm{NCPC}$; superado; e distinguido. Distinção e superação são instrumentos indispensáveis ao desenvolvimento de um sistema de precedentes.

Distinção é uma palavra que assume duas acepções na linguagem jurídica. Primeiramente, é um método de confronto entre o caso e o precedente. Proceder à distinção é proceder a um confronto entre o caso e o precedente, pode ser chamado de distinção método. $\mathrm{Na}$ outra acepção, distinção é o resultado a que se chega após esse confronto, identificando peculiaridades no caso que o distingue e que, por isso, não se aplica o precedente. 23

O juízo de distinção não é um juízo que revoga o precedente ou que desrespeita o precedente, contrariando-o, mas sim o interpretando pra dizer que ele não se aplica àquele caso. Não há precedente em que a aplicação dispense a distinção. A distinção é uma atividade imprescindível na jurisdição, pois sempre será possível. Fazer a distinção é comparar o caso sub judice com o caso paradigma, ou seja, com o caso que gerou o precedente. Não se deve compará-lo com a súmula, mas sim comparar os casos.

Nesse sentido, vale dizer que o relatório da sentença foi valorado no novo CPC porque ajudará no momento do confronto. O código regulamentou a distinção nos casos de recurso repetitivo. Quando o STJ e o STF no julgamento de recursos repetitivos mandarem paralisar todos os processos à espera da decisão é direito da parte requerer a distinção do caso para retirá-lo da suspensão. $\mathrm{O}$ art. 1.037 do novo CPC regulamenta longamente a temática. A

23 DIDIER JR, Fredie; BRAGA, Paula Sarno; DE OLIVEIRA, Rafael Alexandria. Op. cit., p. 559. 
petição requerente a distinção deve ser dirigida para o juízo na qual ficou o processo sobrestado, que por sua vez concederá o contraditório. Se a distinção não for conhecida, caberá recurso, ou seja, o novo CPC prevê um recurso para demonstrar a distinção, relevando a importância dada pelo sistema ao instituto. Esse regulamento está definido para o julgamento de recursos repetitivos e não para o incidente de resolução de demandas repetitivas, todavia, de modo analógico se aplica tal previsão, porque eles compõem um microssistema de formação de precedentes obrigatórios, as normas se complementam, compondo um mesmo sistema. ${ }^{24}$

Superação de um precedente significa revoga-lo, mudando sua orientação. Um sistema de precedentes não vive sem a superação, porque ele que dá essência ao sistema. Não contradiz a estabilidade, porque ser estável não significa ser eterno e tem haver com a proibição de mudanças abruptas. Conforme a sociedade muda, a percepção sobre o direito muda, por isso que é possível superar o precedente. Mas, a superação requer um regramento.

Quem revoga o precedente é o Tribunal que o criou. São diversos os motivos que justificam a superação: mudanças na percepção social, ou seja, aspectos sociais e morais relacionados aos costumes; transformação do modo de ver o direito; e a possiblidade de atualizar rapidamente o direito.

A superação de um precedente que vigora a muito tempo, de modo a fazer com que as pessoas pautem a sua conduta nele, tem de ter uma eficácia modulada. Não se pode superar um precedente longevo destruindo tudo o que foi feito com base nele, porque as pessoas acreditavam nele como precedente obrigatório de um Tribunal Superior. Autorizar essa superação traria insegurança e quebraria a confiança do povo na atividade jurisdicional. Assim, a superação de um precedente longevo não terá eficácia retroativa, poderá beneficiar aquele que conseguiu a superação, mas não funcionará como parâmetro para desfazer o que foi feito anteriormente, pois viola obscenamente a segurança jurídica, a confiança e a boa-fé. No entanto, nada impede que o Tribunal supere o precedente para aplicação futura, ou seja, não supera no próprio caso, mas avisa que em nenhum outro caso será julgado daquela maneira. ${ }^{25}$

\footnotetext{
24 Id., ibid., p. 526.

25 DIDIER JR, Fredie; BRAGA, Paula Sarno; DE OLIVEIRA, Rafael Alexandria. Op. cit. p, 526.
} 
Pela primeira vez é incorporado no texto processual, o princípio da proteção da confiança e da isonomia, impossibilitando a superação implícita, isso porque os Tribunais passam a ter com todos os cidadãos uma relação institucional, que impõe o dever de, se for mudar a jurisprudência, fazer uma convocação, modular os efeitos, fundamentar especificadamente, "dialogar" com os fundamentos passados, atentando para a proteção da confiança, segurança jurídica e isonomia. 26

Destaca-se ainda que a aplicação do stare decisis pode horizontal ou vertical. Horizontal quando há respeito aos próprios precedentes e à própria jurisprudência vinculante, vertical quando há respeito à jurisprudência vinculante e a precedentes de Cortes a que subordinados os órgãos jurisdicionais que avaliam o caso subsequente. Diz-se que o art. 926 estatui o stare decisis horizontal, e o art. 927, o vertical. 27

\section{ROL DOS PRECEDENTES NO NOVO CPC}

O sistema de precedentes obrigatórios foi devidamente lançado no texto processual com a vigência do novo CPC, nos termos do art. 927.

A decisão do STF em controle concentrado de constitucionalidade é vinculante, ou seja, deve ser observado por todos. Essa regra existe desde a Constituição Federal, contudo, o efeito vinculante (erga omnes) é da coisa julgada. Esse inciso estabelece que o precedente em ADIN, ADC e ADPF seja observado, e não a coisa julgada que já era vinculante, ou seja, não se refere ao dispositivo, mas sim à ratio decidendi.

Estão previstos os precedentes cuja ratio decidendi foi enunciada em súmula vinculante.

São precedentes obrigatórios ainda, os acórdãos em IAC, IRDR e em julgamento de recursos extraordinário e especial repetitivos, consoante inciso III do art. 927 do NCPC. Precedentes construídos nos incidentes de resolução de demandas repetitivas e de assunção de

26 Id., ibid., p. 559.

27 SALLES, Carlos Alberto de. Precedentes e jurisprudência no novo CPC (LGL\2015 $\backslash 1656)$ : novas técnicas decisórias? In GRINOVER, Ada Pellegrini et al. O Novo Código de Processo Civil - Questões controvertidas. 1. ed., São Paulo: Atlas, 2015 
incompetência são obrigatórios, pois vão organizar e reunir todos os argumentos favoráveis e contrários à determinada tese jurídica para, uma vez fazendo essa coleta formar um precedente obrigatório.

Esses incidentes ao lado do procedimento formal para criação de súmula vinculante e os procedimentos de criação de precedentes obrigatórios são procedimentos criados para a construção de precedentes obrigatórios, esses procedimentos formam um microssistema de formação concentrada de precedentes obrigatórios. A súmula vinculante, o IAC, o IRDR e os recursos repetitivos se juntam aos recursos de revista repetitivos (lei 13015) e forma o microssistema, as regras de um e outro devem ser aplicadas a todos. Tudo que disser respeito à formação do precedente obrigatório de modo concentrado se aplica todos eles. Audiências públicas, amicus curiae, coleta de todos os argumentos favoráveis e contrários à tese, dar publicidade, são marcas do microssistema de formação concentrada de precedentes obrigatórios, que é composto por súmula vinculante, IAC, IRDR, julgamento de recursos extraordinário e especial repetitivos e recursos de revista repetitivos. 28

Enunciados das súmulas do STF em matéria constitucional e do STJ em matéria infraconstitucional (federal) e a orientação do plenário ou do órgão especial aos quais estiverem vinculados, também obrigam a observância. Essa vinculação não é nacional, mas local e interna, porque os tribunais ficam vinculados aos próprios precedentes e, hierárquica, na medida em que os juízes da primeira instância relacionados àquele tribunal ficam vinculados a ele.

\subsection{INCIDENTE DE RESOLUÇÃO DE DEMANDAS REPETITIVAS}

Uma das grandes inovações no novo CPC é o incidente de resolução de demandas repetitivas, que resolve casos idênticos através do julgamento de um único caso, utilizando-se para tanto a questão de direito, a ratio decidendi.

Marinoni esclarece o conceitualmente o IRDR como uma técnica processual:

O incidente de resolução é uma técnica processual destinada a criar uma solução para a questão replicada nas múltiplas ações pendentes. Bem por isso, como é obvio, a decisão proferida no incidente de resolução de demandas repetidas apenas resolve casos idênticos. Essa a distinção básica entre o sistema de precedentes das Cortes

28 DIDIER JR, Fredie; BRAGA, Paula Sarno; DE OLIVEIRA, Rafael Alexandria. Op. cit., p. 530. 
Supremas e o incidente destinado a dar solução a uma questão litigiosa de que podem provir múltiplos casos. ${ }^{29}$

Julgado o IRDR, a ratio decidendi será aplicada a todos os processos individuais ou coletivos que versem sobre idêntica questão de direito e que tramitem na área de jurisdição do respectivo tribunal e aos casos futuros que versem idêntica questão de direito e que venham a tramitar no território de competência do tribunal. 30

Luiz Guilherme Marinoni reforça, dizendo:

A circunstância de o incidente de resolução tratar de "casos idênticos" tem clara repercussão sobre o raciocínio que dá origem à decisão judicial. Essa decisão obviamente não é elaborada a partir da regra da universabilidade, ou seja, da regra que determina que um precedente deve ser aplicável ao maior número de espécies possíveis de casos. A decisão de resolução de demandas repetitivas objetiva regular uma só questão infiltrada em casos que se repetem ou se multiplicam. ${ }^{31}$

Eduardo Talamini define causas repetitivas como "ações entre sujeitos total ou parcialmente diversos, mas que concernem a uma mesma questão de direito". ${ }^{32}$ Nos casos de ações idênticas, inobstante o pleito de cada ação seja único, a questão jurídica a ser julgada é idêntica e afetará todos os casos semelhantes.

O incidente autoriza os Tribunais julgar casos repetitivos com base em um caso que servirá como paradigma e que tenham, sobretudo, como objeto controvertido uma mesma e única questão de direito. Depois de selecionado o caso paradigma, a questão jurídica repetitiva deve ser identifica para discussão, desde que retrate adequadamente a controvérsia.

A decisão no incidente não busca resolver todos os casos semelhantes possíveis, mas sim a questão de direito idêntica infiltrada em tantos outros casos.

Teresa Arruda Alvim Wambier entende que o IRDR contribui, indiscutivelmente com a celeridade processual, otimizando a prestação jurisdicional e, por consequência, diminuindo o numero de processos. Além disso, a uniformização jurisprudencial é uma das missões

\footnotetext{
${ }^{29}$ MARINONI, Luiz Guilherme. O "problema" do incidente de resolução de demandas repetitivas. Revista Argumentum - RA, eISSN 2359-6889, Marília/SP, V. 17, pp. 45-64, Jan-Dez. 2016. Disponível em: < ojs.unimar.br/index.php/revistaargumentum/article/download/313/62>. Acesso em 06 jun. 2017, p. 43.

30 SIMÃO, Lucas Pinto. O incidente de resolução de demandas repetitivas ("IRDR"). Disponível em: < www.pucsp.br/tutelacoletiva/download/incidente-de-resolucao >. Acesso em 08 jun. 2017.

${ }^{31}$ MARINONI, Luiz Guilherme. Op. cit., p. 44.

32 TALAMINI, Eduardo. Incidente de resolução de demandas repetitivas (IRDR): pressupostos. Disponível e m : < w w w. m i g a $1 \mathrm{~h}$ a s . c o m. b r / d e P e s o / 1 6, M I 236580 , 31047 Incidente+de+resolucao+de+demandas+repetitivas+IRDR+pressupostos $>$. Acesso em: 10 jun. 2017.
} 
levantadas pelo no códex, sendo possível através do IRDR, tanto que tratou de disciplinar tal regra em artigo especial (art. 926, NCPC). 33

Por sua vez, Eduardo Talamini afirma que o IRDR:

Não é - e jamais pode ser interpretado como - um instrumento de redução da carga de trabalho, a qualquer custo, dos tribunais. Essa visão autoritária do IRDR é desautorizada por sua disciplina no CPC - além de ser obviamente incompatível com as garantias constitucionais do processo. 34

Fato é que o IRDR funda-se em princípios e objetivos que visam a economia processual, previsibilidade, segurança jurídica e isonomia.

O IRDR exige o preenchimento de pressupostos de admissibilidade, devendo ser atendidos de forma simultânea, como prevê o art. 976, inciso I: efetiva repetição de processos, que a controvérsia sobre a mesma questão unicamente de direito e exista risco de ofensa à isonomia e à segurança jurídica.

“O caráter repetitivo da demanda, justificador do incidente, é determinado pela reiteração de uma questão essencialmente jurídica". ${ }^{35}$ No que se refere a mesma questão unicamente de direito a "lei quer referir-se aos casos em que, na hipótese de serem os aspectos fáticos incontroversos (o que vai ter de se aferir em cada processo), tem-se basicamente uma mesma questão jurídica a se resolver - e essa situação repete-se em inúmeros processos". 36

Os processos estarão correndo risco de ofensa à isonomia e à segurança jurídica quando em casos idênticos soluções distintas estiverem sendo proferidas, mais precisamente quando a mesma questão jurídica, em diversos casos, receber decisões diferentes.

O art. 977 do novo código legitima o magistrado, as partes, o ministério público ou a defensoria pública para requererem a instauração do IRDR, em petição a ser dirigida para o Presidente do respectivo Tribunal.

\subsection{INCIDENTE DE ASSUNÇÃO DE COMPETÊNCIA}

\footnotetext{
${ }^{33}$ WAMBIER, Teresa Arruda Alvim. Op. cit.

34 TALAMINI, Eduardo. Op. cit.

35 Id., ibid.

36 Id., ibid.
} 
O NCPC (Novo Código de Processo Civil), em seu art. 947 permite que o relator submeta o julgamento de determinada causa ao órgão colegiado de maior abrangência dentro do tribunal, conforme regimento interno. Tal permissão cabe em qualquer recurso, remessa necessária ou nas causas de competência originária.

Sem dúvida, é uma nova forma julgamento de processos nos tribunais, baseando-se na relevância do caso concreto, a partir da análise da repercussão social e do interesse público envolvidos na hipótese concreta.

O instrumento pela qual se concretiza essa nova modalidade é o incidente de assunção de competência, estabelecido para ocorrer em duas hipóteses. Quando envolver relevante questão de direito, com grande repercussão social, sem repetição em múltiplos processos; ou quando ocorrer relevante questão de direito a respeito da qual seja conveniente a prevenção ou a composição de divergência entre câmaras ou turmas do tribunal.

Define-se IAC como:

[...] um instrumento jurídico com natureza jurídica de incidente processual, pelo qual se desloca a competência, de um órgão colegiado menor (dito fracionário) para um órgão colegiado maior (seção, grupo de câmaras, órgão especial, pleno) indicado pelo regimento interno do tribunal, quando se tratar de julgamento de recurso, de remessa necessária ou de ações de competência originária do tribunal, quando ficar demonstrada relevante questão de direito e notável repercussão social, desde que não caracterize multiplicidade de processos, com vistas a duas finalidades bem delineadas, uma mediata e outra imediata. ${ }^{37}$

Em outras palavras no IAC há um deslocamento da competência, ou seja, um órgão originariamente competente para julgar um caso, seja ele um recurso, remessa necessária ou ação originária, conforme determinado pelo regimento interno do tribunal, perde sua competência, especialmente para aquele feito, transferindo-se essa competência para um órgão colegiado com maior composição e integrante do mesmo tribunal.

O IAC pretende, inicialmente, que os tribunais cumpram o disciplinado no art. 926, NCPC, ou seja, uniformize a jurisprudência, para que ela se mantenha estável, íntegra e coerente. Outra premissa do incidente é efetivação dos princípios da isonomia e da segurança jurídica à luz do princípio do livre convencimento motivado, devendo não só valer a mesma regra jurídica para todos os jurisdicionados, mas especialmente a mesma conclusão jurídica.

37 MIRANDA, Maylton Rodrigues de. Incidente de assunção de competência: instrumento para a justiça das decisões judiciais. Disponível em: < http://www.conteudojuridico.com.br/ artigo,incidentedeassuncaodecompetenciainstrumentoparajusticadasdecisoesjudiciais,56209.html $>$. Acesso em: 08 jun. 2017. 
Fredie Didier Jr vai além, argumentando que o incidente também se destina a "provocar o julgamento de caso relevante por órgão colegiado de maior composição". 38

Em síntese pode se afirmar que o incidente busca a formação do precedente obrigatório, reduzindo a duração do processo, direcionando o julgador e os jurisdicionados a entendimentos precisos sobre questão de direito, assegurando a isonomia e a segurança jurídica nas decisões judiciais, constitucionalizando o processo.

Assim como o IRDR, o IAC prescinde de requisitos de admissibilidade. Quando pendente causa no tribunal, originária, recursal ou de remessa necessária e quando relevante questão de direito e grande repercussão social. Os requisitos são cumulativos, em resumo devem estar presentes: questão de direito; grande repercussão social; sem repetição em múltiplos processos; existência de interesse público.

Os legitimados a propor o IAC, nos termos do $\S 1^{\circ}$ do art. 947 são: o relator do recurso, quaisquer das partes do processo, o Ministério Público e a Defensoria Pública.

Para Fredie Didier Jr. "o relator, antes ou durante o julgamento do recurso, da remessa necessária ou do processo de competência originária, pode propor, de ofício, a assunção de competência". Ou seja, antes mesmo do relator colocar o feito em pauta para julgamento, poderá propor o IAC, assim como, durante seu voto poderá fazê-lo. No entanto, após o voto estaria impedido pela preclusão consumativa, como leciona Fredie Didier Jr.:

\begin{abstract}
A preclusão consumativa consiste na perda de faculdade/poder processual, em razão de essa faculdade ou esse poder já ter sido exercido, pouco importa se bem ou mal. Já se praticou o ato processual pretendido, não sendo possível corrigi-lo, melhorá-lo ou repeti-lo. A consumação do exercício do poder o extingue. Perde-se o poder pelo exercício dele. 39
\end{abstract}

Além do deslocamento da competência, a formação do precedente obrigatório é outro efeito do IAC. Sem dúvida que essa obrigatoriedade em observar o precedente é o efeito mais relevante, pois fixa uma tese jurídica sobre questão divergente, ou com aptidão para gerar divergência, ou seja, otimiza a atividade jurisdicional, reduzindo o tempo de duração do processo, solucionando casos semelhantes, com a mesma natureza e, acima de tudo, prestigia princípios da isonomia e da segurança jurídica, em consonância com os objetivos precípuos do novo Código de Processo Civil.

38 DIDIER JR, Fredie; BRAGA, Paula Sarno; DE OLIVEIRA, Rafael Alexandria. Op. cit., p. 657.

39 DIDIER JR, Fredie; BRAGA, Paula Sarno; DE OLIVEIRA, Rafael Alexandria p. 537. 


\subsection{DEVERES GERAIS DOS TRIBUNAIS RELACIONADOS AO SISTEMA DE PRECEDENTES JUDICIAIS}

São diversos os deveres estabelecidos para os Tribunais em razão do precedente, com o objetivo de torná-los estáveis, íntegros e coerentes. O art. 10 do NCPC proíbe a decisão surpresa ${ }^{40}$, aquela em que o juiz decide com base em questão que não foi colocada em debate. $\mathrm{O}$ art. $489, \S 1^{\circ}$ trata, especificadamente, dos casos de decisões que não foram fundamentadas, impondo a identificação dos fundamentos determinantes do precedente e do enunciado de sumula quando o julgador proferir sentença, obrigando ainda que seja demonstrado que o caso se enquadra no precedente.

À luz dos artigos retro mencionados, o $\S 1^{\circ}$, do art. 927 disciplina que a decisão com base em precedentes deve observar a questão colocada em debate para proferir sentença, bem como o dever de fundamentar.

Fredie Didier Junior entende que o art. $489, \S 1^{\circ}$ é incompleto ao impor a observância dos artigos supra apenas quando a decisão se embasar em precedentes, isso porque é indispensável a aplicam na própria formação do precedente, ou seja, a formação do precedente exige que não haja surpresa e haja fundamentação. ${ }^{41}$

O novo CPC ao montar esse sistema de precedentes obrigatórios imputa aos Tribunais deveres institucionais para a consolidação e efetivação do sistema, quais sejam: publicidade, uniformização, estabilidade, integridade e coerência.

Quanto ao dever de publicidade, os Tribunais têm o dever (geral) de dar publicidade de seus precedentes, de modo organizado, sistematizado, parametrizado para que as pessoas tenham acesso à pesquisa (art. $\left.927, \S 5^{\circ}\right)$, devendo ser minuciosa e acessível.

A uniformização (art. 926) obriga que os Tribunais uniformizem a jurisprudência, ou seja, não é mais uma faculdade. Inadmissível, com o novo CPC a dispersão jurisprudencial.

A estabilidade (art. 926) visa evitar mudanças repentinas, imotivadas, inesperadas e injustificadas de sua jurisprudência, pois está relacionada à ideia de inércia argumentativa, ou seja, para aplicar o precedente não há necessidade de muitos argumentos, basta dizer que o caso se encaixa no precedente, a carga de motivação é menor no Tribunal, contudo, nos casos

\footnotetext{
40 Id., ibid., p. 540.

41 DIDIER JR, Fredie; BRAGA, Paula Sarno; DE OLIVEIRA, Rafael Alexandria p. 540.
} 
em que for necessário afastar o precedente, a carga de motivação é muito maior, porque significa quebrar a estabilidade.

Além de uniforme, estável e pública, os Tribunais devem manter a jurisprudência íntegra e coerente, consoante art. 926 do NCPC. A teoria do direito contemporâneo usa muito o termo coerência e integridade para se referir ao direito, à ciência jurídica e às decisões judiciais. A coerência e a integridade consistem em dois deveres que visam um mesmo objetivo, a consistência da jurisprudência, que somente serão alcançadas se houver o enfrentamento de todos os argumentos favoráveis e contrários à tese jurídica. É necessária profunda fundamentação. Sendo os deveres contrariados, ou seja, sem integridade e sem coerência, a jurisprudência não tem aptidão para ser universalizada.

O dever de integridade e coerência são dois postulados hermenêuticos, são normas de interpretação do direito, ou seja, o direito há de ser interpretado de modo íntegro e coerente. É preciso ter critérios para aferir a integridade e a coerência, devendo ser examinados a partir de um balanceamento entre eles, ou seja, jamais podem ser examinados isoladamente.

A integridade tem haver com unidade do direito, dizer que a decisão respeita a integridade significa dizer que a decisão respeitou o direito, em toda sua complexidade, porque o direito não é só a Lei ou uma resolução, mas sim um conjunto de normas. A decisão deve ainda respeitar o direito como sistema e não como um amontoado de normas. Desse critério decorre a existência de microssistema jurídico, tal como o sistema de precedentes, que também devem ser respeitados com integridade, porque é preciso pensar no direito como um conjunto organizado de normas.

O primeiro critério da coerência é de que a jurisprudência não deve ser contraditória. A coerência esta relacionada com a completude que, por sua vez, se relaciona com o dever de fundamentação, ou seja, a jurisprudência coerente é aquela que consegue ser produzida a partir do exame de tudo quanto pode ser arguido contra ela, os possíveis argumentos contrários aquela orientação tem que terem sido enfrentados na formação do precedente.

$\mathrm{O}$ respeito às decisões anteriores e o respeito à linha evolutiva do desenvolvimento da jurisprudência devem ser observados para que a jurisprudência se torne coerente, isso porque ela se desenvolve em cadeia, mantendo a lógica, para que não a torne incompreensível. 


\section{CONCLUSÃO}

Fato é que o sistema obrigatório de precedentes trouxe ao Judiciário grande desafio. Não só para os operadores do direito, mas também para o mundo jurídico considerado num todo. Isso porque, temas atuais trouxeram à tona a necessidade de avançar no sentido de promover um processo constitucionalizado e, principalmente, que se aproxima do direito material, sem atuação isolada e unilateral.

Sem dúvida o respeito aos precedentes faz com o que o judiciário encare o direito de maneira uniformizada, estável e previsível, cumprindo as promessas do novo CPC. Apesar de muitos afirmarem que o país, com a adoção dos precedentes, se transforma em um sistema de commow law, não é isso que parece ser. Até porque há muitos anos o judiciário brasileiro observa precedentes para tomada de decisões, inclusive mudando o curso da realidade brasileira. É possível afirmar, portanto, que o Brasil está totalmente apto a adotar o sistema de precedentes obrigatórios sem se transformar em sistema commow law respeitando, sobretudo, o sistema da civil law, ou seja, o Brasil como sistema civil law adotou o sistema obrigatório de precedentes para que seja possível uniformizar, estabilizar e prever o direito.

Através do estudo proposto foi possível constatar tal afirmativa, ao passo que a uniformização, prevista também no novo CPC, ao lado do sistema de precedentes promoverá, certamente, a isonomia e segurança jurídica da atividade jurisdicional. Logo, a promessa de um processo justo, com resultados satisfatórios, à luz dos princípios constitucionais e que promova a segurança jurídica ao jurisdicionado poderá ser, sem dúvida, possível por meio do respeito aos precedentes.

No entanto, o operador do direito deverá utilizar o sistema de precedentes com inteligência, sem utilizá-lo como ferramenta de redução de processos, buscando o Judiciário se socorrer da crise. Será, sem dúvida, uma consequência, uma vez que o judiciário se uniformiza, se estabiliza, atuando de forma previsível e coerente, demandas temerárias serão evitadas pelo próprio jurisdicionado.

Nesse sentido, o sistema não violará garantias processuais fundamentais, ao contrário, coexistirá com os princípios da celeridade processual, da razoabilidade e da proporcionalidade na efetivação do direito, atendendo a força normativa da Constituição Federal. Não há afronta, 
portanto, à Constituição Federal, nem aos princípios de acesso à justiça. Mas, todos devem coexistir possibilitando a efetividade do direito.

\section{REFERÊNCIAS}

DIDIER JR, Fredie; BRAGA, Paula Sarno; DE OLIVEIRA, Rafael Alexandria. Curso de Direito Processual Civil: teoria da prova, direito probatório, ações probatórias, decisão, precedente, coisa julgada e antecipação dos efeitos da tutela. 11 ed. Salvador: Editora JusPodivm, 2016.

; SOUZA, Marcus Seixas. Formação do precedente e amicus curiae no direito imperial brasileiro: o interessante dec. 6.142/1876. Revista de Processo, vol. 220/2013, p. 407 - 421, Jun.2013.

. O respeito aos precedentes como diretriz histórica do direito brasileiro.

Revista de Processo Comparado, vol. 2/2015, p. 99 - 120, Jul - Dez. 2015.

DONIZETTI, Elpídio. A força dos precedentes no Novo Código de Processo Civil.

Disponível em: < www.revistas.unifacs.br>. Acesso em: 01 jun. 2017.

FERACINE, Luiz. Os primeiros princípios do saber. SoLivros/Uniderp, 1999.

FUX, Luiz. A Súmula Vinculante E O Superior Tribunal De Justiça. Revista de Direito Bancário e do Mercado de Capitais, vol. 28, p. 27, Abr. 2005.

JESUS, Priscilla Silva de. Teoria do precedente judicial e o novo código de processo civil. Disponível em: < http://www.revistas.unifacs.br/index.php/redu/article/view/3240>. Acesso em: 05 jun. 2017.

KOOPMANS, Thomas. Stare decisis in European Law. Leiden University Repository. Disponível em: $<$ https://openaccess.leidenuniv.nl/handle/1887/22742>. Acesso em 23 jun. 2017.

LOURENÇO, Haroldo. Precedente judicial como fonte do direito: algumas considerações sob a ótica do novo CPC. Disponível em: <www.agu.gov.br/page/download/index/id/ 11458380>. Acesso em 30 mai. 2017.

MARINONI, Luiz Guilherme. O "problema” do incidente de resolução de demandas Repetitivas. Revista Argumentum - RA, eISSN 2359-6889, Marília/SP, V. 17, pp. 45-64, JanDez. 2016. Disponível em: < ojs.unimar.br/index.php/revistaargumentum/article/download/ 313/62>. Acesso em 06 jun. 2017.

MIRANDA, Maylton Rodrigues de. Incidente de assunção de competência: instrumento para a justiça das decisões judiciais. Disponível em: < http://www.conteudojuridico.com.br/ 
artigo,incidentedeassuncaodecompetenciainstrumentoparaajusticadasdecisoesjudiciais, 56209.html>. Acesso em: 08 jun. 2017.

SALLES, Carlos Alberto de. Precedentes e jurisprudência no novo CPC

(LGL L2015\1656): novas técnicas decisórias? In GRINOVER, Ada Pellegrini et al. O Novo Código de Processo Civil - Questões controvertidas. 1. ed., São Paulo: Atlas, 2015

SIMÃO, Lucas Pinto. O Incidente De Resolução De Demandas Repetitivas (“IRDR"). Disponível em: < www.pucsp.br/tutelacoletiva/download/incidente-de-resolucao $>$. Acesso em 08 jun. 2017.

TALAMINI, Eduardo. Incidente de resolução de demandas repetitivas (IRDR): pressupostos. Disponível em:<www.migalhas.com.br/dePeso/16,MI236580,31047Incidente + de + resolucao + de + demandas + repetitivas + IRDR + pressupostos $>$. Acesso em: 10 jun . 2017.

THEODORO JÚNIOR, Humberto. Jurisprudência e precedentes vinculantes no novo código de processo civil: demandas repetitivas. Revista de Processo, vol. 255/2016, p. 359 372, Maio. 2016.

GERAIGE NETO, Zaiden. O princípio da inafastabilidade do controle jurisdicional: art. $5^{\circ}$, inciso XXXV. da Constituição Federal. São Paulo: Editora Revista dos Tribunais, 2003, p. 17.

WAMBIER, Teresa Arruda Alvim. Estabilidade e adaptabilidade como objetivos do direito: civil law e common law. In: Revista de Processo, São Paulo: RT, v. 172, ano 34, p. 129, jun. 2009. Disponível em: < http://www.egov.ufsc.br/portal/sites/default/files/ estabilidade_e_adaptabilidade_como_objetivos_do_direito_civil.pdf $>$. Acesso em: 03 jun. 2017.

Interpretação da lei e de precedentes: civil law e common law. Revista dos Tribunais, vol. 893/2010, p. 33 - 45, Mar. 2010, Doutrinas Essenciais de Direito Civil, vol. 1, p. 1347 - 1359, Out. 2010. 